\section{Reflexiones entorno a la extensión en la facultad de Educación de la Usco}

Comité de Extensión

de la Facultad de Educación

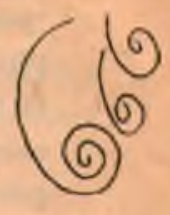

La esencia de la extensión universitaria estriba en su carácter de proceso de gestión social que posibilita la intervención de la Universidad en el desarrollo regional y nacional, con miras a llegar a intervenciones al interior del conflicto social y a la búsqueda de soluciones concretas que expresen la idea de desarrollo entendida como cambio social desde la perspectiva de los sectores populares. Naturalmente que esta intervención no debe ser vista como algo puramente coyuntural, sino como un proceso permanente ajustado a la búsqueda de modelos alternativos de desarrollo. Esta concepción de la extensión implica que debe estar estrechamente correlacionada con las funciones de investigación y docencia que cumple la institución universitaria. En el primer caso, a través de investigaciones sobre la realdiad regional y nacional que orienten sobre qué problemas debe actuar la acción de la extensión universiaria, y, en el segundo caso, a través de la contextuali-zación de los contenidos de las asignaturas para que el conocimien to pueda aplicarse con intención transformadora.

La anterior visión de la extensión universitaria puede profundizarse a partir de dos consideraciones sobre la misión de la Universidad Surcolombiana y el concepto de desarrollo contenidos en materiales ela-borados por la Comisión de Recstructuración de la Universidad. A continuación se presenta una sintesis de tales consideraciones:

a. La Misión central de la Universidad Surcolombiana es desarrollar el conoci-miento científico, académico y popular adecuado a las necesidades de todas las gentes de la región a fin de que puedan alcanzar mayores niveles de desarrollo en todos los órdenes de la vida.
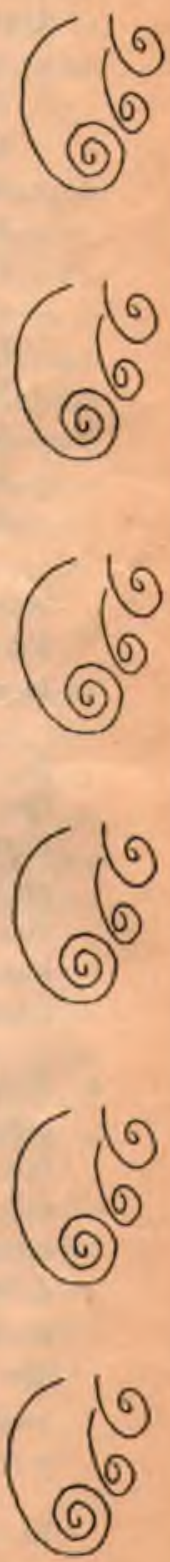
b. El concepto de desarrollo se presenta como un proceso integral, equitativo y sostenible apoyado en conocimientos cientificos, tecnológicas y humanisticos que se obtengan sobre la región, y en el diálogo permanente con las empresas, gremios, comunidades e instituciones.

Las anteriores consideraciones permiten presentar también el concepto de extensión bajo otros ángulos tales como:

1. El diálogo entre el saber académico y los saberes populares para $s$ mutua cualificación dirigida al desarrollo integral de la región.

2. La extensión universitaria concebida como teniendo un carácter interdisciplinario e interinstitucional.

3. Sin que constituya su esencia, pero tam-poco como algo que pueda ser excluido, la extensión universitaria puede también pensarse como venta de servicios a gremios y empresas en el campo de la elaboración y ejecución de proyectos, en el área de procesos de educación permanente o en el ámbito de la planeación y ejecución de cursos de actualización o nivelación en disciplinas específicas.

4. La extensión universitaria, en su carácter de proceso de gestión social, constituye una responsabilidad social compartida que requiere de la participación de las distintas instituciones gubernamentales, las organizaciones civiles, los gremios económicos y la comunidad en general.

5. En correlación con lo anterior, la extensión universitaria puede pensarse también como un espacio adecuado para la creación de una cultura de la participación en la región como requisito para intervención consciente de los distintos sectores sociales en los procesos del desarrollo integral de la comunidad huilense.

6. La extensión universitaria puede concebirse como un escenario adecuado para el análisis pluralista de problemas regionales en el sentido que permitiria considerarlos desde el ángulo de distintas disciplinas y de las potencialidades regionales, lo cual haria posible varias alternativas de solución.

7. Finalmente la extensión a nivel de la Facultad de Educación debe desarrollar los programas y proyectos de formación de docentes tanto de la Universidad como del Departamento del Huila en los diversos niveles y especialidades.

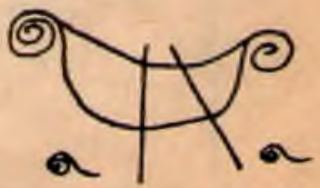

